\title{
Reservoirs performances under climate variability: a case study
}

\author{
A. LONGOBARDI, M. MAUTONE \& C. DE LUCA \\ Department of Civil Engineering, University of Salerno, Italy \\ alongobardi@unisa.it
}

\begin{abstract}
A case study, the Piano della Rocca dam (southern Italy) is discussed here in order to quantify the system performances under climate variability conditions. Different climate scenarios have been stochastically generated according to the tendencies in precipitation and air temperature observed during recent decades for the studied area. Climate variables have then been filtered through an ARMA model to generate, at the monthly scale, time series of reservoir inflow volumes. Controlled release has been computed considering the reservoir is operated following the standard linear operating policy (SLOP) and reservoir performances have been assessed through the calculation of reliability, resilience and vulnerability indices (Hashimoto et al. 1982), comparing current and future scenarios of climate variability. The proposed approach can be suggested as a valuable tool to mitigate the effects of moderate to severe and persistent droughts periods, through the allocation of new water resources or the planning of appropriate operational rules.
\end{abstract}

Key words reservoir; drought mitigation; climate variability

\section{INTRODUCTION}

Water resources system management is a very complicated task and, when dealing with climate variability, it becomes even more challenging. As an example, the climate variability on which during the last few decades many researchers have focused their efforts, can indeed seriously compromise the operation of reservoirs, and this study aims to investigate this issue. A comparison of reservoir performances, assessed through the calculation of reliability, resilience and vulnerability indices (Hashimoto et al. 1982), between present and future scenarios of climate variability is reported here. A number of studies presented in the recent past, have demonstrated that the combination of a simulation approach coupled with a performance assessment via indices evaluation is a valuable tool to measure the sensitivity of reservoirs to climate variability and prolonged droughts (Karamouz and Araghinejad 2008, Jain 2010, Preziosi et al. 2013).

The Piano della Rocca case study is illustrated in this paper; a rock filled dam reservoir, located along the Alento River in southern Italy, a reservoir planned for domestic and irrigation water demand and hydropower production.

As the first step, the present situation is assessed and considered as the baseline for future discussion. An ARMA model is calibrated, at the monthly time scale, for the estimated stream inflow time series corresponding to the present situation, and it is further used to generate future scenario stream inflow time series, under different climate forcing scenarios. Different climate scenarios are, on their side, generated according to the tendencies in precipitation and air temperature observed during the last decades for the studied area, as reported in related investigations (Longobardi and Villani 2010, Longobardi and Mautone 2014). The proposed approach can be suggested as a valuable tool to mitigate the effects of moderate to severe and persistent drought periods through the allocation of new water resources or the planning of appropriate operational rules.

\section{CASE STUDY}

The Piano della Rocca dam is a rock-filled dam located along the Alento River, southern Italy, which consists of a 612-m-long and 40-m-high gravity section with a crest elevation of $125 \mathrm{~m}$ above sea level. The catchment contributing to Piano della Rocca Lake is a $200 \mathrm{~km}^{2}$ impervious drainage area, located in a humid region that receives mean annual rainfall of about $1100 \mathrm{~mm}$ and mean annual inflow of about $430 \mathrm{~mm}$. The main purposes of the dam are power generation, flood control, and water supply. The reservoir has a maximum surface area of about $2.12 \mathrm{~km}^{2}$ and a maximum storage capacity of about $28.5 \mathrm{hm}^{3}$. 


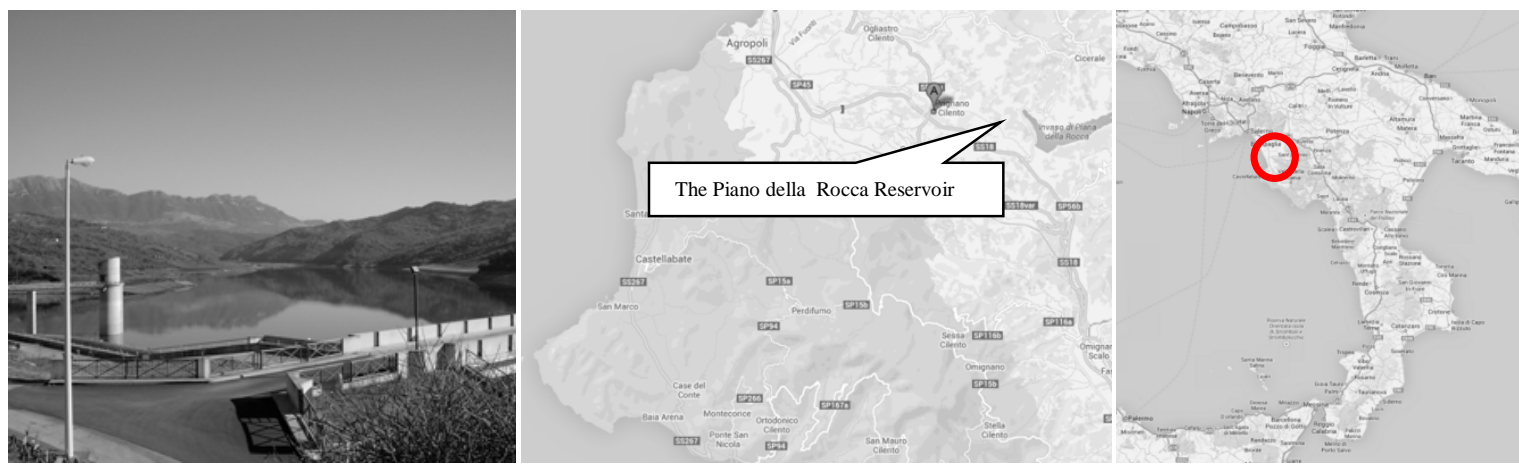

Fig. 1 The Piano della Rocca reservoir on the Alento River, southern Italy.

Available data consist of rainfall, air temperature, water levels, water demand, for the time period 2000-2013. The time series of stream inflow to the artificial lake is estimated by solving the continuity equation for the unknown inflows.

Water balance, at the daily scale, in the Piano della Rocca dam reservoir, has been formulated as:

$$
\mathrm{S}_{\mathrm{t}}+\left(\mathrm{Q}_{\mathrm{t}}+\mathrm{P}_{\mathrm{t}}\right)-\left(\mathrm{E}_{\mathrm{t}}+\mathrm{R}_{\mathrm{t}}+\mathrm{Sp}_{\mathrm{t}}\right)=\mathrm{S}_{\mathrm{t}+1}
$$

where, at each time step t, $\mathrm{S}$ is the water storage, $\mathrm{Q}$ is the reservoir inflow, $\mathrm{P}$ is the precipitation directly falling into the reservoir, $\mathrm{E}$ is the evaporation loss, $\mathrm{R}$ is the water release and $\mathrm{Sp}$ is the spillway controlled release. Reconstructed reservoir inflow volume, aggregated at the monthly scale, is illustrated in Fig. 2, for the period of available measurements.
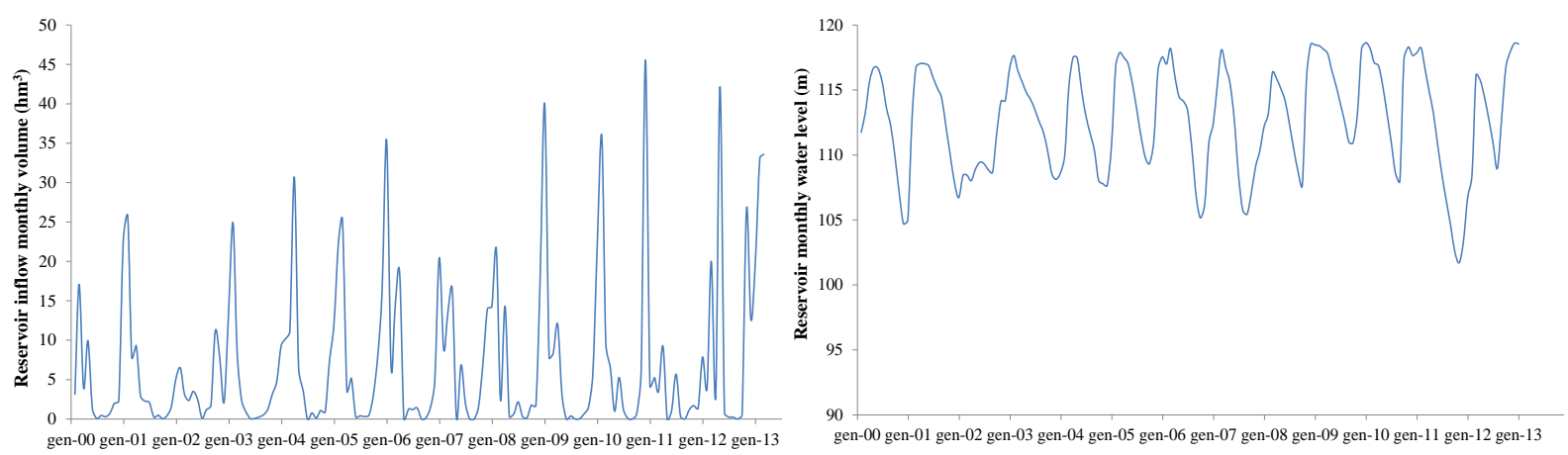

Fig. 2 Reconstructed reservoir monthly inflow volume (left panel) and observed reservoir monthly water level (right panel) for the available measurements period.

\section{HYDROLOGICAL MODELLING}

At the monthly scale, streamflow can be modelled as the sum of direct, interflow and groundwater components. When dealing with impervious watersheds, the groundwater contribution can be neglected, and only the first two components have to be modelled. In such cases, the catchment can be described as a linear reservoir, representing the seasonal interflow with a seasonal time delay $\mathrm{K}$ and a uniform recharge coefficient a, and a linear channel, routing the net rainfall to the catchment outlet as the direct runoff component (Claps et al. 1993, Guida et al. 2006, Longobardi and Villani 2006). In this hypothesis, coupling the linear reservoirs balance equations with the whole system balance equation, total streamflow $\mathrm{Q}$ at each time step is related to the net input by means of an ARMA $(1,1)$ model, which stochastic formulations corresponds to:

$$
\mathrm{Q}(\mathrm{t})-\Phi \mathrm{Q}(\mathrm{t}-1)=\varepsilon(\mathrm{t})-\Theta \varepsilon(\mathrm{t}-1)
$$

where $\varepsilon$ is the model residual, a periodic independent random process, to which the net rainfall input I is related, and $\Phi$ and $\Theta$ are the model stochastic parameters, related to the model conceptual parameters K (reservoirs response time) and a (reservoir recharge coefficient). 
In its original formulation, the model algorithm, starting from an observed streamflow time series, can calibrate the model and estimates both the parameters and, because of the univariate approach with an inverse procedure, the net rainfall input $\mathrm{I}(\mathrm{t})$, the distributed basin runoff prior to the routing process. For simulation purposes, once model parameters have been calibrated for a particular catchment, the probabilistic rainfall net input model can be used to generate stochastic net input time series and model equation (2) can be used to simulate the corresponding hydrologic time series. On a probabilistic base, the I(t) series can indeed be reasonably represented by the Bessel distribution (Benjamin and Cornell 1970), which is the sum of a Poissonian number of events with exponentially distributed intensity:

$$
\begin{array}{ll}
\mathrm{P}[\mathrm{I}=0]=\mathrm{e}^{-\mathrm{v}} & \mathrm{I}=0 \\
\mathrm{f}_{\mathrm{I}}(\mathrm{I})=\mathrm{e}^{-\lambda \mathrm{I}-\mathrm{v}}(\mathrm{U} / \mathrm{I}) \mathfrak{I}_{1}\left[2\left(\mathrm{U} \lambda \mathrm{I}^{1 / 2}\right]\right. & \mathrm{I}>0
\end{array}
$$

where $\lambda=1 / \beta$ is the exponential parameter, $v$ is the Poisson parameter and $\mathfrak{J}_{1}(\mathrm{x})$ is the modified Bessel function of order 1 . The reconstructed reservoir inflow monthly time series has been used to calibrate the catchment model parameters, which result as $\Phi=0.501$ and $\Theta=0.038$, that is also $\mathrm{K}$ $=1.44$ months and $\mathrm{a}=0.609$. The rainfall net input has also been inversely reconstructed and the probabilistic model parameters, at the monthly scale, estimated and illustrated in Fig. 3. Figure 3 also shows the fit between water balance reconstructed and ARMA modelled reservoir inflow time series.
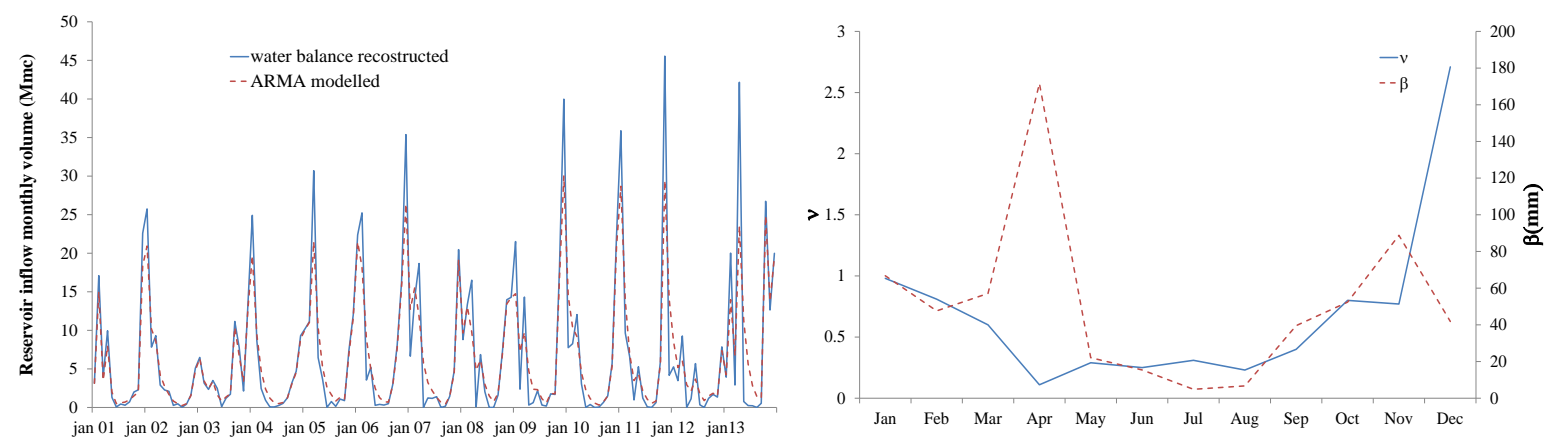

Fig. 3 Water balance reconstructed and modelled reservoir monthly inflow volume (left panel) and net rainfall input distribution $v$ and $\beta$ parameters (right panel).

\section{FUTURE CLIMATE SCENARIO GENERATION}

The probabilistic I $(\mathrm{t})$ model has been used to stochastically generate the net rainfall scenario, under different future potential climate conditions, to further assess the impact of climate variability on reservoir performance. Future potential climate conditions are based on previous climatological studies concerning the investigated area at different spatial scale.

On a global scale, the 4th IPCC report (IPCC 2007) indicates as future projection (2070-2099) for the Mediterranean basin, an increase in summer temperature, up to $5.5^{\circ} \mathrm{C}$ or $4^{\circ} \mathrm{C}$ according to $\mathrm{A} 2$ and B2 scenarios, respectively, and a decrease in mean annual precipitation by up to $30-45 \%$. Furthermore, according to the 4th IPCC report, climate change is likely to have an impact on water resources that will see a reduction in runoff production up to $20-30 \%$ in the investigated area. Global projections are confirmed by the climate tendencies observed at the regional scale. Over about the last century, at the annual scale, the area has been characterized by a negative tendency in total rainfall, of about $11.59 \mathrm{~mm} /$ decade, corresponding to about $10 \%$, and a positive tendency in air temperature, of about $0.17^{\circ} \mathrm{C} /$ decade (Longobardi and Villani 2010, Longobardi and Mautone 2014). At the seasonal scale, the rainfall tendency is negative, except during the summer trimester; this particular condition would bring the monthly precipitation to move from a seasonal to a uniform distribution during the year. Air temperature is instead featured by a positive trend for each of the considered seasons with a larger magnitude during the winter season. 
According to the global and regional scale studies mentioned, two long term future climate scenarios, CSI and CSII, have been generated and compared to the current climate scenario CS0, assumed as the baseline. The probabilistic I(t) model (equation (3)) has been used to stochastically generate the CSI and CSII net rainfall scenarios, calibrating the $\beta$ and $v$ parameters to have a net rainfall reduction, or equally a runoff reduction, of about $10 \%$ and $20 \%$, respectively. Main statistics, at the monthly and annual scale, are illustrated in Table 1 . Future climate scenarios are also plotted in Fig. 4 (right panel), where differences in average and variance are evident.

Table 1 Net rainfall statistics at the monthly and annual scale, for different climate scenarios.

\begin{tabular}{lllllll}
\hline & $\begin{array}{l}\text { Monthly } \\
\text { Mean (mm) }\end{array}$ & $\begin{array}{l}\text { Variance } \\
(\mathrm{mm})\end{array}$ & $\mathrm{Cv}$ & $\begin{array}{l}\text { Annual } \\
\text { Mean (mm) }\end{array}$ & $\begin{array}{l}\text { Variance } \\
(\mathrm{mm})\end{array}$ & $\mathrm{Cv}$ \\
\hline CS 0 & 35.7 & 60.9 & 1.7 & 428.9 & 186.0 & 0.4 \\
CS I & 32.3 & 54.1 & 1.7 & 388.1 & 151.1 & 0.4 \\
CS II & 27.9 & 44.4 & 1.6 & 334.6 & 131.2 & 0.4 \\
\hline
\end{tabular}

\section{RESERVOIR PERFORMANCE UNDER CLIMATE VARIABILITY}

The Piano della Rocca reservoir performance is measured on an index-based approach, referring to a number of indices proposed by Hashimoto et al. (1982): reliability, resilience and vulnerability.

Reliability $r_{t}$ is the probability that the system state lies in the set of satisfactory states (no failure):

$$
r_{t}=1-\left(f_{p} / n\right) \quad 0 \leq r_{t} \leq 1, f_{p} \leq n
$$

where $f_{p}$ is the number of failure periods out of $n$ periods in total.

The resilience $\left(\gamma_{\text {mean }}\right)$ describes how quickly a system is likely to recover from failure. If $d_{j}$ is the duration of each failure event, then the resilience can be expressed as:

$$
\gamma_{\text {mean }}=\left[\frac{1}{N} \sum_{j=1}^{N} d_{j}\right]^{-1}
$$

The vulnerability $\mathrm{V}_{\text {mean }}$ indicates the magnitude of the failure event measuring the volumetric failure event deficit. If $\mathrm{D}$ is the target demand and $\mathrm{R}$ is the controlled release, the deficit volume for each failure event can be calculated as:

$$
\mathrm{v}_{\mathrm{j}}=\sum_{\mathrm{t}=1}^{\mathrm{d}_{\mathrm{j}}}\left[\mathrm{D}_{\mathrm{t}}-\mathrm{R}_{\mathrm{t}}\right]
$$

and the vulnerability of the system as (Kjeldsen and Rosbjerg 2004):

$$
\mathrm{V}_{\text {mean }}=\frac{1}{\mathrm{~N}} \sum_{\mathrm{j}=1}^{\mathrm{N}} \mathrm{vj}
$$

The failure events, which equations (4)-(7) refer to, represent the period where the controlled release $\mathrm{R}$ does not meet the target demand requirements. Thus, to quantify the reservoir performances under climate variability scenarios it would be necessary to compare target demand and controlled release for each of the generated climate scenario. The monthly time scale has been considered here.

The daily multiple planned water consumptions of the reservoir under investigation is depicted in Fig. 4, where a monthly scale variability has been considered. The environmental release and hydropower water demand are set on a minimum and constant value of $100 \mathrm{~L} / \mathrm{s}$ and $350 \mathrm{~L} / \mathrm{s}$, respectively. Domestic and irrigation water consumption are instead featured by a seasonal pattern, with the largest water demands occurring during the hot summer season. 

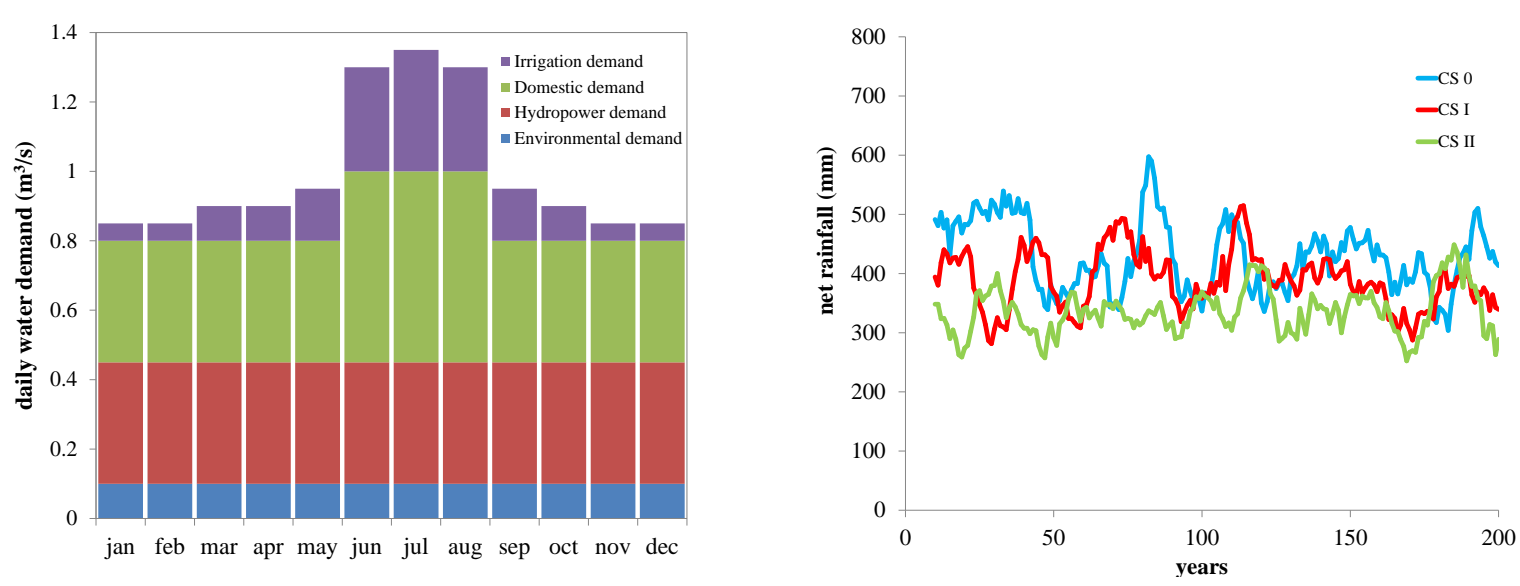

Fig. 4 Daily water demand, on a monthly base, divided by irrigation, domestic, hydropower and environmental consumptions (left panel) and 10-years moving average for net rainfall (right panel)

Controlled release, for each net rainfall scenario, has been computed considering the reservoir is operated following the standard linear operating policy SLOP, summarized in equation (8) (Jain and Singh 2003). Considering $A w_{t}$ the sum of the $S$ reservoir volume storage at time $t-1$ and $Q$, the net reservoir inflow volume at the same time $t$, the controlled release $R_{t}$ can be operated according to the following rules:

$$
\begin{array}{ll}
\text { if } \mathrm{Aw}_{\mathrm{t}} \leq \mathrm{D}_{\mathrm{t}} & \mathrm{R}_{\mathrm{t}}=\mathrm{S}_{\mathrm{t}} \\
\text { if } \mathrm{D}_{\mathrm{t}}<\mathrm{Aw}_{\mathrm{t}} \leq \mathrm{S}_{\max }+\mathrm{D}_{\mathrm{t}} & \mathrm{R}_{\mathrm{t}}=\mathrm{D}_{\mathrm{t}} \\
\text { if } A \mathrm{Aw}_{\mathrm{t}}>\mathrm{S}_{\max }+\mathrm{D}_{\mathrm{t}} & \mathrm{R}_{\mathrm{t}}=A \mathrm{Aw}_{\mathrm{t}}-\mathrm{S}_{\max }
\end{array}
$$

where $S_{t}$ is updated at each time step through the continuity equation (1) and $S_{\max }$ is the maximum reservoir storage.

The quantification of performance indices is illustrated in Fig. 5, as time series of failure duration and volumes, and also in Table 2 as average indices. Clearly a decrease in water availability, which occurs moving from CS 0 to CS II, causes a reduction in the reservoir performance indices.
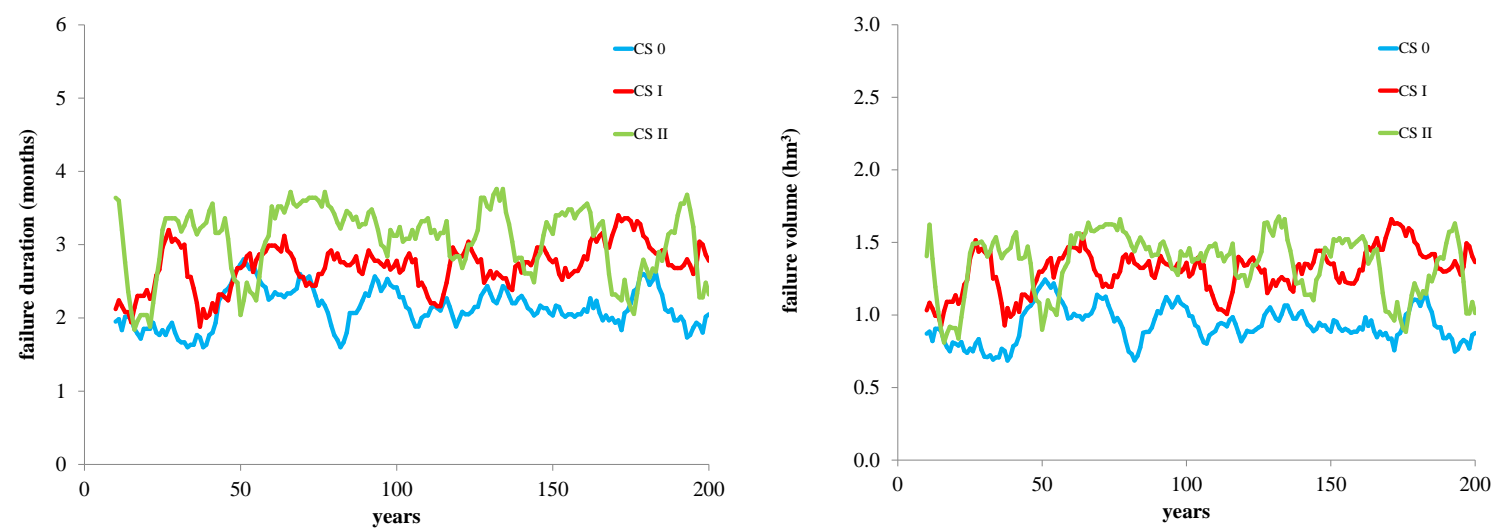

Fig. 5 Ten-years moving average for failure duration (left panel) and failure volume (right panel) for different climate scenarios.

Table 2 Performance indices for different climate scenarios.

\begin{tabular}{llll}
\hline & CS 0 & CS I & CS II \\
\hline Average $\mathrm{n}^{\circ}$ failure & 166 & 191 & 207 \\
Reliability $(\mathrm{r})$ & 0.93 & 0.92 & 0.92 \\
Resilience $(\gamma-$ months) & 2.1 & 2.5 & 2.8 \\
Vulnerability $\left(\mathrm{V}-\mathrm{hm}^{3}\right)$ & 0.92 & 1.39 & 1.53 \\
\hline
\end{tabular}




\section{CONCLUSION AND DISCUSSION}

This paper has illustrated the results of an analysis of system performance under climate variability scenarios for the Piano della Rocca Reservoir (southern Italy). Net rainfall time series have been stochastically generated, according to the climatological studies reported both at the global and regional scale for the studied area, and filtered through an ARMA model to generate time series of reservoir inflow volumes. Controlled release has been computed considering the reservoir is operated following the standard linear operating policy (SLOP) and reservoir performance has been assessed through the calculation of reliability, resilience and vulnerability indices, comparing current CS 0 and future scenarios CS I and CS II, characterized by a progressive reduction in net precipitation mean values, corresponding to the mean runoff reduction, of about $10 \%$ and $20 \%$. System failure appears to be mainly caused by the reduction in water availability rather than by the reservoir capacity and performance indices quantify an increase in the duration and deficit volume, even though the performance reduction under future projections does not appear dramatic. The highlighted findings, even though conceptually valid, could be biased by the number of simplifications considered here. The variability in the target demand, for the long term period, should indeed be accounted for whilst herein a future rate equal to the current one has been considered. Moreover, improvements in terms of rainfall scenario generation should be considered to better represent the increase in the precipitation inter-annual variability, indicated in the 4th IPCC report, and not herein fully considered as the different net rainfall scenarios show a similar coefficient of variation. Improvements are indeed also planned in terms of generation of rainfall scenarios at a finer time scale, to further account for the enhancement is the magnitude of severe rain events which could potentially be the cause of additional system failure for reservoir capacity excess.

Acknowledgments The authors wish to thank the Consorzio Velia, ing. M. Nicodemo and dr. F. Chirico, for having kindly provided the Piano della Rocca reservoir data used in the presented analysis. Authors also wish to thank anonymous reviewer's comments and suggestions, which resulted in an improvement of the study.

\section{REFERENCES}

Benjamin, J. R. and Cornell, C. A. (1970) Probability, Statistics and Decision for Civil Engineering. McGraw-Hill, New York.

Claps, P., Rossi, F. and Vitale, C. (1993) Conceptual-stochastic modelling of seasonal runoff using autoregressive moving average models at different scales of aggregation. Water Resources Research 29(8), 2545-2559.

Guida, D., Longobardi, A. and Villani, P. (2006) Hydrological modelling for river basin management in a highly hydro-geological conditioned environment. Transactions on Ecology and the Environment 89, 283-292.

Hashimoto, T., Loucks, D. P. and Stedinger, J. (1982) Reliability, resilience and vulnerability for water resources system performance evaluation. Water Resources Research 18(1), 14-20.

IPCC. (2007) Climate change. In: The IPCC Fourth Assessment Report (ed. by M. L. Parry et al.). Cambridge University Press: New York, NY.

Jain, S. J. and Singh, V. P. (2003) Water Resources Systems Planning and Management. Elsevier, Amsterdam.

Jain, S. J. (2010) Investigating the behaviour of statistical indices for performance assessment of a reservoir. Journal of Hydrology 391, 90-96.

Kjeldsen, T. R. and Rosbjerg, D. (2004) Choice of reliability, resilience and vulnerability estimators for risk assessments of water resources systems. Hydrological Sciences Journal 49(5), 755-767.

Karamouz, M. and Araghinejad, S. (2008) Drought mitigation through long-term operation of reservoirs: case study. Journal of Irrigation and Drainage Engineering 134(4), 471-478.

Longobardi, A. and Villani, P. (2006) Seasonal response function for daily streamflow investigation. Physics and Chemistry of the Earth 31, 1107-1117.

Longobardi, A. and Villani, P. (2010) Trend analysis of annual and seasonal rainfall time series in a Mediterranean area. International Journal of Climatology 30 (10), 1538-1546.

Longobardi, A. and Mautone, M. (2014) Trend analysis of annual and seasonal air temperature time series in southern Italy. IAEG XII Congress Torino, September 15-19 (submitted).

Preziosi, E., et al. (2013) Vulnerability to drought of a complex water supply system. The upper Tiber basin case study (Central Italy). Water Resources Management 27, 4655-4678. 